\section{HEART FAILURE}

\section{Angiotensin receptor blockers for chronic heart failure and acute myocardial infarction}

John J V McMurray

Clinical Research Initiative in Heart Failure, Wolfson Building, University of Glasgow, Glasgow, UK
Correspondence to: Professor JJV McMurray, CRI in Heart Failure, Wolfson Building, University of Glasgow, Glasgow G12 8QQ, UK

J.McMurray@bio.gla.ac.uk
T wo landmark clinical trials, CONSENSUS I and SOLVD-T, have shown, unequivocally, that angiotensin converting enzyme (ACE) inhibitors reduce all cause mortality in patients with chronic heart failure $(\mathrm{CHF})$ and underlying left ventricular systolic dysfunction. ${ }^{12}$ These and other trials have also confirmed that ACE inhibitors reduce morbidity, as manifest by hospital admission, in patients with $\mathrm{CHF}^{3}$

A number of other key randomised, controlled, trials have also shown that ACE inhibitors reduce the risk of all cause mortality and major clinical events (sudden death, reinfarction, heart failure) after myocardial infarction. ${ }^{\mathrm{w} 1-3}$ These benefits are most clearly seen in patients with left ventricular systolic dysfunction or clinical evidence of heart failure. ${ }^{\mathrm{w} 4}$

The ATLAS study has shown that higher doses of ACE inhibitor give greater morbidity/ mortality benefits. ${ }^{\text {w5 }}$

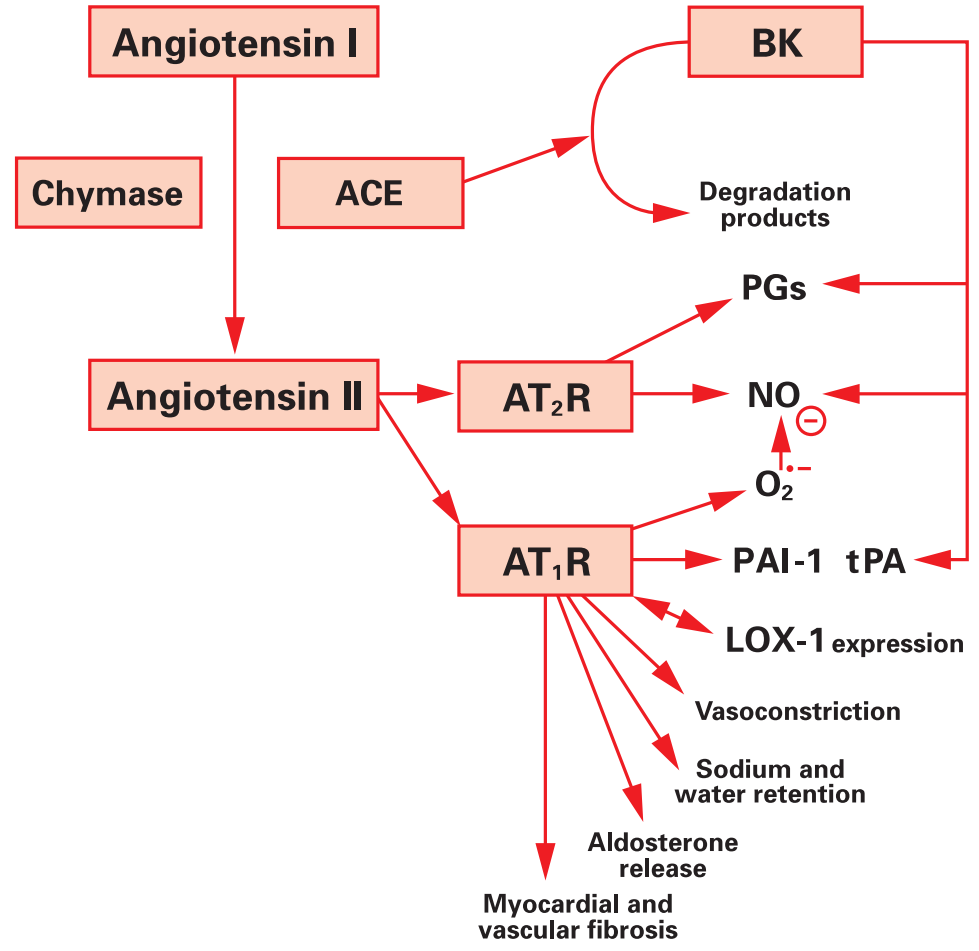

Figure 1. Known and postulated actions of angiotensin converting enzyme (ACE) and angiotensin II, and pathways for angiotensin II generation. tPA, tissue plasminogen activator; PAl-1, plasminogen activator inhibitor 1; BK, bradykinin; $\mathrm{O}_{2}^{--}$, superoxide anion radical; NO, nitric oxide; LOX-1, lectin-like oxidised low density lipoprotein $(\mathrm{LDL})$ receptor- $1, \Theta, \mathrm{O}_{2}^{--}$neutralises nitric oxide; $\longrightarrow \longrightarrow$, oxidised LDL induces $\mathrm{AT}_{1} \mathrm{R}$ expression/angiotensin II induces LOX-1 through $\mathrm{AT}_{1} \mathrm{R}$.
Recently, another drug known to block a component of the renin-angiotensinaldosterone system (RAAS), spironolactone (an aldosterone antagonist), has also been shown to reduce mortality and morbidity in $\mathrm{CHF}$, even when added to an ACE inhibitor (this was demonstrated in RALES). ${ }^{\mathrm{w}} 6$

The question arises, therefore, as to what the role of the newest agents available for RAAS inhibition, the angiotensin II receptor antagonists or blockers (ARBs), might be in $\mathrm{CHF}$ and acute myocardial infarction?

\section{ARB-ACE inhibitor comparison} studies

Though, logically, the first question to ask of ARBs might be whether these new drugs are better than placebo, the first comparison actually made in a large scale trial was with an ACE inhibitor. The first of these-the ELITE-1 trial-addressed tolerability, whereas the hypothesis of the larger ELITE-2 trial was that losartan would be more efficacious than captopril. The approach of the ELITE trials was based on the belief that: (1) ARBs are more effective inhibitors of the RAAS than ACE inhibitors; and (2) bradykinin, the breakdown of which is blocked by ACE inhibitors, is directly or indirectly responsible for cough and possibly other adverse effects of these agents. ${ }^{4}$ There is some scientific basis for the view that ARBs might be more efficacious than ACE inhibitors at blocking the RAAS. If it is accepted that ACE inhibitors bring about benefit through reducing the actions of angiotensin II, then the recent demonstration that angiotensin II generating pathways that bypass ACE exist in human myocardium and arteries is of some significance (fig 1). ${ }^{\text {w7-9 }}$ Clearly, these observations suggest that ARBs offer a potentially more effective means of inhibiting the actions of angiotensin II. Arguably, the ATLAS and RALES trials also support the view that more intense inhibition of the RAAS might be better. ${ }^{\mathrm{w} 5} \mathrm{w} 6$ This hypothesis, however, needed to be tested in one or more definitive morbidity/ mortality trials-for example, ELITE-2 (see below). Selective blockade of the angiotensin (AT) II receptor subtype, with hyperstimulation of the unblocked $\mathrm{AT}_{2}$ receptor by displaced angiotensin II, is also more attractive, theoretically, than reduced stimulation of both receptor subtypes with an ACE inhibitor (fig 1 ). This is because the $\mathrm{AT}_{2} \mathrm{R}$ may mediate biological actions which are the opposite of those that follow $\mathrm{AT}_{1} \mathrm{R}$ activation (and, hence, potentially favourable in $\mathrm{CHF}$ ). How have these hypotheses stood the test of clinical trials?

Tolerability: SPICE and ELITE-1

If $\mathrm{ARBs}$ are no more efficacious than ACE inhibitors, but are better tolerated, then there may be potentially substantial public health benefit to be gained. Though we do not yet know if ARBs are as efficacious as ACE inhibitors (see below), we do know ARBs are better tolerated. ARBs do not cause cough and do not seem to cause more of any other adverse effect 
Table 1 Angiotensin receptor blocker (ARB) trials in chronic heart failure (CHF): number of patients and main inclusion criteria

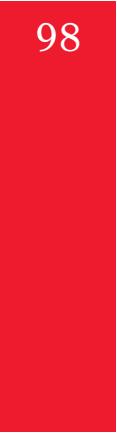

\begin{tabular}{|c|c|c|c|}
\hline & ELITE-2 & Val-HeFT & CHARM \\
\hline $\begin{array}{l}\text { Number of patients } \\
\text { Entry criteria }\end{array}$ & $\begin{array}{l}3152 \\
-\geqslant 60 \text { years }(85 \% \geqslant 65) \\
\text { - NYHA class II-IV } \\
\text { - }>70 \% \text { IHD } \\
\text { LVEF } \leqslant 0.40 \\
\text { - No ACE-I/ARB within } 3 \text { months } \\
-525 \% \beta \text { blocker }\end{array}$ & $\begin{array}{l}5010 \\
\text { - NYHA class II-IV } \\
\text { LVEF < } 0.40 \text { and LVIDD }>2.9 \\
\mathrm{~cm} / \mathrm{m}^{2} \\
\text { - Usual background therapy (most } \\
\text { ACE-I) }\end{array}$ & $\begin{array}{l}7601 \\
\bullet \text { NYHA class II-IV } \\
\text { (1) LVEF } \leqslant 0.40 \text { ACE-I intolerance arm } \\
(n=2028) \\
\text { (2) LVEF } \leqslant 0.40 \text { ACE-I/ARB combination arm } \\
(n=2548) \\
\text { (3) LVEF }>0.40 \text { arm }(n=3025)\end{array}$ \\
\hline Treatment groups & Captopril $v$ losartan & $\begin{array}{l}\text { Placebo } v \text { valsartan (background } \\
\text { ACE-I) }\end{array}$ & $\begin{array}{l}\text { Placebo } v \text { candesartan-no ACE-I }(1) \text { placebo } v \\
\text { candesartan-background ACE-I }(2+3)\end{array}$ \\
\hline
\end{tabular}

LVEF, left ventricular ejection fraction; NYHA, New York Heart Association; ACE-I, angiotensin converting enzyme; IHD, ischaemic heart disease; LVIDD, left ventricular internal dimension.

than ACE inhibitors. Certainly, the SPICE trial found that candesartan was well tolerated by patients deemed to be ACE inhibitor intolerant by their physician. ${ }^{5}$ In the ELITE-1 study $20.8 \%$ of captopril treated patients discontinued treatment because of an adverse event (excluding death) compared to $12.2 \%$ of losartan treated patients $(\mathrm{p} \leqslant 0.002) .{ }^{46}$ The more recent ELITE-2 study supports this finding, reporting that $14.5 \%$ of patients withdrew from captopril because of adverse effects, compared to $9.4 \%$ from losartan $(\mathrm{p}<0.001) .^{78}$

Efficacy: ELITE-1, RESOLVD, and ELITE-2 The ELITE-1 study reported the surprising finding that patients with $\mathrm{CHF}$ treated with losartan had a lower mortality than patients treated with captopril. ${ }^{4}$ This trial was not designed to test this hypothesis and was too small to prove, with confidence, that ARBs have superior efficacy to ACE inhibitors. The RESOLVD study, comparing candesartan cilexetil (candesartan) to enalapril did not support the findings of ELITE-1. ${ }^{910}$

Recently, a large, prospective, properly powered, study has compared an ACE inhibitor (captopril) to an ARB (losartan). ${ }^{78}$ ELITE-2 was designed to test the hypothesis that losartan was more efficacious than captopril (tables 1, 2, and 3). ${ }^{78}$ This hypothesis was not proven - that is, losartan was not superior to captopril (table 4). ELITE-2 cannot, strictly speaking, answer any more questions than the one asked. It cannot tell us whether losartan is "as good as" (equivalent to) captopril or, at least, no worse than (not inferior) to captopril. These terms have strict statistical and regulatory definitions that the design and results of ELITE-2 do not fulfil. ${ }^{\text {w10 }}$ w11 Indeed, ELITE-2 cannot even tell us if losartan is superior to placebo. ${ }^{\text {w12 }}$

\section{ARB-ACE inhibitor combination studies}

The second question, addressed by a major clinical trial, was whether ARB-ACE inhibitor combination therapy is better than ACE inhibitor monotherapy. The hypothesis underlying this approach is very different from that underlying the ELITE studies. While the belief that ARBs are better inhibitors of the RAAS is shared by both hypotheses, the combination
Table 2 Angiotensin receptor blocker (ARB) trials in chronic heart failure $(C H F)$ : hypotheses tested

\begin{tabular}{|c|c|c|c|c|}
\hline & \multirow{2}{*}{$\frac{\text { Non-inferiority }}{A R B \leqslant A C E-I}$} & \multicolumn{3}{|c|}{ Superiority } \\
\hline & & $A R B>$ placebo & $A R B>A C E-I$ & $A R B+A C E-I I>A C E-I$ \\
\hline ELITE-2 & No & No & $\begin{array}{l}\text { Yes } \\
(25 \%, \mathrm{P} 90 \%) \dagger\end{array}$ & No \\
\hline Val-HeFT & No & No & No & Yes $(20 \%$, P $90 \%)+\dagger$ \\
\hline CHARM & No & $\begin{array}{l}\text { Yes }\left(\mathrm{LVEF} \leqslant 0.40^{\star}\right. \\
18 \%, \mathrm{P} 94 \% \mathrm{LVEF} \\
\left.>0.40^{\star \star} 18 \%, \mathrm{P} 86 \%\right)\end{array}$ & No & Yes ( $18 \%, \mathrm{P} 90 \%)+\dagger$ \\
\hline
\end{tabular}

P, power- that is, power of study to detect that risk reduction (for example, Val HeFT has a 90\% power to detect a $20 \%$ relative risk reduction in mortality with valsartan compared to placebo). ${ }^{\star}$ Assuming an annual placebo group event rate of $24 \%$; $\star \star$ assuming an annual placebo group event rate of $13 \%$; $\leqslant$ not significantly inferior to; fassuming a captopril group annual mortality rate of $9.4 \%$; ††assuming placebo group annual mortality rate of $12 \%$; t†tassuming an annual placebo group event rate of $18 \%$.

See table 1 for key to abbreviations.

therapy approach takes the view that bradykinin is "good" rather than "bad"." This is because bradykinin may enhance the production of nitric oxide and possibly other vasoactive mediators, such as vasodilator prostanoids in vascular and other tissues. ${ }^{\text {w13-15 }}$ Bradykinin may also stimulate tissue plasminogen activator release from the endothelium and favourably influence coagulation/fibrinolysis balance. ${ }^{\text {w16 }}$ Consequently, combination ARBACE inhibitor therapy may give optimum RAAS inhibition and the putative benefits of bradykinin accumulation, through inhibition of its breakdown.

A number of relevant "mechanistic" and "pilot" clinical studies preceded what was

Table 3 Clinical characteristics of the patients enrolled in ELITE-2 and Val-HeFT

\begin{tabular}{lcc}
\hline & ELITE-2 & Val-HeFT \\
\hline Number of patients & 3152 & 5010 \\
Mean age (years) & 71 & 63 \\
Males (\%) & 70 & 80 \\
NYHA class (\%) & 52 & 62 \\
II & 43 & 36 \\
III & 5 & 2 \\
IV & 31 & 27 \\
LVEF (\%) & & \\
Concomitant diagnoses (\%) & 79 & 57 \\
Coronary aetiology & 49 & - \\
Hypertension & 30 & 12 \\
Atrial fibrillation & 24 & 24 \\
Diabetes mellitus & & \\
Drug treatment (\%) & 78 & 86 \\
Diuretic & $-\dagger$ & 93 \\
ACE inhibitor & 50 & 67 \\
Cardiac glycoside & 22 & 34 \\
B Blocker & & \\
\hline
\end{tabular}

* "History of ischaemia" in ELITE-2.

+Patients randomised to either losartan or captopril (23\% of patients had received prior ACE inhibitor) 
Table 4 ELITE-2 end points

\begin{tabular}{|c|c|c|c|c|}
\hline \multirow[b]{2}{*}{ End point } & \multicolumn{2}{|c|}{ Number of patients } & \multirow[b]{2}{*}{$H R(95 \% C I)$} & \multirow[b]{2}{*}{$p$ Value } \\
\hline & $\begin{array}{l}\text { Losartan } \\
(n=1578)\end{array}$ & $\begin{array}{l}\text { Captopril } \\
(n=1574)\end{array}$ & & \\
\hline All cause mortality & $280(17.7 \%)$ & $250(15.9 \%)$ & $1.13(0.95$ to 1.35$)$ & 0.16 \\
\hline $\begin{array}{l}\text { Sudden death or resuscitated } \\
\text { cardiac arrest }\end{array}$ & $142(9.0 \%)$ & $115(7.3)$ & $1.25(0.98$ to 1.60$)$ & 0.08 \\
\hline $\begin{array}{l}\text { Combined total mortality or } \\
\text { hospitalisation for any reason } \\
\text { Hospital admissions (all causes) }\end{array}$ & $\begin{array}{l}752(47.7 \%) \\
659(41.8 \%)\end{array}$ & $\begin{array}{l}707(44.9 \%) \\
638(40.5 \%)\end{array}$ & $\begin{array}{l}1.07(0.97 \text { to } 1.19) \\
1.04(0.94 \text { to } 1.16)\end{array}$ & $\begin{array}{l}0.18 \\
0.45\end{array}$ \\
\hline
\end{tabular}

$\mathrm{HR}$, hazard ratio; CI, confidence interval.

expected to be the first definitive large scale trial, Val-HeFT, exploring this hypothesis. ${ }^{11}$

\section{Small scale studies testing combination therapy}

There is conflicting clinical evidence that some of the effect of ACE inhibitors may be caused by the blocking effect these drugs have on bradykinin breakdown. Two recent studies in hypertensive individuals and healthy subjects, using a selective bradykinin inhibitor, supports such an action, though another in heart failure does not. ${ }^{\text {w13-15 }}$ These mechanistic findings are supported by some clinical observations. Dunselman reported that substitution of telmisar$\tan$ (10-80 mg once daily) for enalapril (10 mg twice daily) in patients with heart failure led to an increase in blood pressure (the REPLACE study), thus supporting the possibility that ACE inhibitors have an additional hypotensive mechanism of action compared to ARBs. ${ }^{12}$ Baruch and colleagues studied the immediate and four week haemodynamic and neurohumoral effects of placebo, valsartan $80 \mathrm{mg}$ twice daily or valsartan $160 \mathrm{mg}$ twice daily added to conventional treatment (including an ACE inhibitor) in patients with $\mathrm{CHF} .{ }^{13}$ Compared to placebo, high dose valsartan reduced pulmonary capillary wedge pressure and systolic blood pressure acutely and after one month's treatment. Valsartan $80 \mathrm{mg}$ and $160 \mathrm{mg}$ twice daily significantly reduced aldosterone at four weeks. Not all studies have supported these findings, however, and there remains the nagging doubt that similar benefits might be obtained by using a bigger dose of ACE inhibitor, rather than adding an ARB. ${ }^{\mathrm{w} 17 \text { w18 }}$ However, Hamroff and colleagues reported a small but impressive six month randomised trial in which patients with moderately severe CHF were randomised to placebo or losartan $50 \mathrm{mg}$ once daily. ${ }^{14}$ All were receiving full conventional treatment including an ACE inhibitor given in an adequate dose (for example, the mean daily dose of enalapril was $32 \mathrm{mg}$ ). The primary end points were exercise capacity and New York Heart Association (NYHA) functional class. Both improved significantly and losartan was well tolerated. In the RESOLVD pilot study the combination of enalapril and candesartan had significantly more favourable effects on the left ventricular remodelling than either monotherapy. ${ }^{9}{ }^{10}$ Clinical outcome was not, however, better in the candesartan-enalapril combination group. The hypothesis that combination therapy is the optimum had, therefore, to be tested in a large scale morbidity-mortality trial.

\section{Trial acronyms}

AIRE Acute Infarction Ramipril Efficacy ATLAS Assessment of Treatment with Lisinopril And Survival

CHARM Candesartan in Heart failure:

Assessment of Reduction in Mortality and Morbidity

CONSENSUS-1 Co-operative North Scandanavian Enalapril Survival Study

ELITE Evaluation of Losartan In The Elderly

HOPE Heart Outcomes Prevention Evaluation

OPTIMAAL Optimal Therapy in Myocardial infarction with the Angiotensin II Antagonist Losartan

PEP-CHF Perindopril for Elderly People with Chronic Heart Failure

RALES Randomised Aldactone Evaluation Study

REPLACE Replacement of angiotensin converting enzyme inhibition

RESOLVD Randomized Evaluation of Strategies for Left Ventricular Dysfunction SAVE Survival and Ventricular Enlargement

SOLVD-T Treatment arm of the Studies Of Left Ventricular Dysfunction

SPICE Study of Patients Intolerant of Converting Enzyme Inhibitors

STRETCH Symptom, Tolerability, Response to Exercise Trial of Candesartan cilexetil in Heart failure

TRACE Trandolapril Cardiac Evaluation Val-HeFT Valsartan Heart Failure Trial V-HeFT Vasodilator Heart Failure Trial VALIANT Valsartan In Acute myocardial infarction

\section{Val-HeFT trial}

The key features of the design of Val-HeFT trial are shown in tables 1 and $2 .{ }^{11}$ The demographic characteristics and preliminary results of Val-HeFT were presented by J Cohn at the 73rd scientific sessions of the American Heart Association (AHA) in New Orleans, 15 November 2000, and all of the subsequent information reported in this review has been obtained from that presentation. The principal hypothesis tested by Val-HeFT was that adding valsartan to conventional treatment (including an ACE inhibitor and $\beta$ blocker, where appropriate) would improve clinical outcome. The co-primary end points were: (1) mortality (all cause); and (2) mortality or morbidity (where morbidity included hospitalisation for $\mathrm{CHF}$, resuscitated sudden death, and administration of intravenous inotropic or vasodilator treatment for $\mathrm{CHF}$ for $\geqslant 4$ hours). Secondary end points included change in NYHA functional class, signs and symptoms of CHF, left ventricular ejection fraction, and quality of life. Val-HeFT randomised 5010 patients, the clinical characteristics of whom are summarised in table $3 .{ }^{11}{ }^{15}$ The average follow up time was approximately 1.9 years. 
The principal results of the Val-HeFT trial, as presented at the AHA, are shown in table 5 . Valsartan did not reduce mortality but did significantly reduce the combined morbidity/ mortality end point by approximately $13 \%$ $(p=0.009)$. This effect was principally caused by a substantial $27 \%$ reduction in CHF hospitalisation (table 5, p =0.00001). There were similarly impressive and significant improvements in the other secondary outcomes presented. At face value, therefore, Val-HeFT would appear to be a "positive" trial, with significant improvements in pre-specified coprimary and secondary end points. Unfortunately, however, the story may not be that simple. This is because Cohn went on to present detailed subgroup analyses which appeared to raise important questions about the overall findings of Val-HeFT.

Firstly, outcomes in the small minority (7\%) of patients not taking on ACE inhibitor at baseline were compared to those in patients taking an ACE inhibitor. The former group had an approximately $45 \%$ reduction in mortality/morbidity compared to a $12 \%$ reduction in the latter. In other words, this analysis raises the possibility that most of the benefit in the overall trial can be explained by a particularly large effect in patients not receiving an ACE inhibitor. To complicate matters further, patients receiving a $\beta$ blocker at baseline (about $35 \%$ ) were compared to those not taking a $\beta$ blocker. The hazard ratio for the mortality/ morbidity end point in patients taking a $\beta$ blocker was 1.15 (that is, there was a trend for such patients to do worse on valsartan) compared to 0.78 in those not on a $\beta$ blocker. In other words, this and some further analysis raised the possibility that "triple neurohumoral blockade" (ACE inhibitor, $\beta$ blocker, ARB) has no advantage over double blockade and may even be disadvantageous. It must be emphasised that subgroup analysis of this type is fraught with danger, can be very misleading, and should only be regarded as hypothesis generating. ${ }^{\text {w19 }}$ Unfortunately, however, the $\beta$ blocker subgroup analysis has attracted much attention because $\beta$ blockers, along with ACE inhibitors, are now regarded as mandatory treatment for CHF. The issue is further confounded by an apparently similar $\beta$ blocker interaction in ELITE-2 (captopril treated patients did better than losartan treated patients if receiving $\beta$ blocker treatment at baseline). ${ }^{8}$

Where then do we stand with ARBs following both ELITE-2 and Val-HeFT? I would have to conclude that the picture still remains unclear. From a purist perspective Val-HeFT does suggest that adding an ARB to conventional treatment reduces morbidity (CHF hospitalisation). How much attention one should pay to subgroup analyses is very debatable. Before reaching any firm conclusion we must at least wait for full publication of the Val-HeFT results. It must be reiterated that only preliminary data are available at the time of writing. Analysis of the neurohumoral and left ventricular remodelling data from this study should give additional insight into the
Clinical pharmacology of ARBs versus ACE inhibitors

Angiotensin II exerts its known biological actions via the angiotensin II type 1 receptor $\left(A T_{1} R\right)$. The angiotensin receptor blockers (ARBs) currently available for clinical use selectively antagonise the action of angiotensin II at the $\mathrm{AT}_{1} \mathrm{R}$

- The role of the angiotensin II type 2 receptor $\left(A T_{2} R\right)$ is uncertain. It may, when stimulated, increase the production of nitric oxide and other vasodilator/anti mitotic substances. The $\mathrm{AT}_{2} \mathrm{R}$ is hyperstimulated during selective $\mathrm{AT}_{1} \mathrm{R}$ blockade in vivo

- Angiotensin II may be generated through the action of ACE and, probably, chymase on angiotensin $\mathrm{I}$. There may be additional "non-ACE" pathways for angiotensin II production. $\mathrm{AT}_{1} \mathrm{R}$ blockers (but not $\mathrm{ACE}$ inhibitors) antagonise the effects of angiotensin II generated by "non ACE" pathways

- ACE is also known as kininase II which degrades bradykinin (that is, bradykinin accumulates during ACE inhibition). Bradykinin may, directly or indirectly, cause some of the adverse effects of ACE inhibitors (for example, cough) but may also have beneficial vasodilator, growth, and fibrinolytic actions.

issues raised above. We will also have a more complete picture when the CHARM programme completes. ${ }^{16}$ This three study programme is now ideally poised to address some of the remaining uncertainty about ARBs. ${ }^{16}$ In particular, CHARM includes a study in patients not taking an ACE inhibitor (study 0003 or "alternative CHARM"-see below), and more patients in the ACE-I + ARB combination arm of CHARM (study 0006 or "added CHARM") are receiving a $\beta$ blocker at baseline than in Val-HeFT (55\% v 35\%) and all are taking an ACE inhibitor, allowing further exploration of any potential ARB- $\beta$ blocker interaction.

\section{ARB-placebo comparison studies}

Remarkably, it has been generally assumed that $\mathrm{ARBs}$ are an effective treatment for $\mathrm{CHF}$ (that is, superior to placebo) even though there are very few data to support this assumption.

Table 5 Val-HeFT end points (preliminary)

\begin{tabular}{llllll}
\hline \multirow{2}{*}{ End point } & \multicolumn{2}{l}{ Number of patients } & & \\
\cline { 2 - 4 } & $\begin{array}{l}\text { Valsartan } \\
(n=2511)\end{array}$ & $\begin{array}{l}\text { Placebo } \\
(n=2499)\end{array}$ & $R R(95 \%$ CI $)$ & p Value \\
\hline $\begin{array}{l}\text { All cause mortality } \\
\begin{array}{l}\text { Combined all cause mortality }+ \\
\text { morbidity }\end{array}\end{array}$ & $495(19.7 \%)$ & $484(19.4 \%)$ & $1.02(0.90$ to 1.15$)$ & 0.800 \\
$\begin{array}{l}\text { Heart failure hospitalisations } \\
\text { (patients) }\end{array}$ & $723(28.88 \%)$ & $801(32.1 \%)$ & $0.87(0.79$ to 0.96$)$ & 0.009 \\
\hline
\end{tabular}


Table 6 Angiotensin receptor blocker (ARB) trials in post-myocardial infarction patients: number of patients and main inclusion criteria

\begin{tabular}{lll}
\hline & OPTIMAAL & VALIANT \\
\hline Number of patients & 5476 & $14500^{\star}$ \\
Entry criteria & $\begin{array}{l}\text { new years. Anterior Q wave MI or } \\
\text { nVB }\end{array}$ & $\begin{array}{l}\text { LVSD and/or signs of heart } \\
\text { failure }\end{array}$ \\
Treatment groups & captopril losartan & captopril valsartan \\
& & captopril + valsartan
\end{tabular}

*Target number.

MI, myocardial infarction; LBBB, left bundle branch block; LVSD, left ventricular systolic dysfunction.

Clearly, the widely held opinion that ARBs are efficacious in $\mathrm{CHF}$ is based on the view that RAAS inhibition is beneficial, a perception based on the belief that ACE inhibitors and spironolactone exert their effect in this way. While almost certainly true, at least in part, even the most apparently obvious hypotheses should be tested in medicine.

\section{Small studies comparing ARBs to placebo in CHF}

ARBs, like ACE inhibitors, have favourable acute and chronic neurohumoral and haemodynamic actions in CHF. ${ }^{10}{ }^{13-17}$ w17 w18 w20 There are, however, remarkably few data showing any clinical benefit of ARBs over placebo. A recent trial, STRETCH, has shown that one of these agents, candesartan cilexetil, can improve exercise tolerance in $\mathrm{CHF}$ in a dose dependent manner, compared to placebo. ${ }^{18}$ This has not, however, been a consistent finding in all studies (there are two fairly large, unpublished, exercise studies showing no benefit of losartan over placebo). ${ }^{\mathrm{w} 21}$ Meta-analyses of relatively small trials with losartan and candesartan have, however, suggested that ARBs might improve clinical outcomes when compared to placebo, though an imputed placebo analysis of ELITE-2 (using SOLVD-T as the historical control) gives only weak support to these meta-analyses. ${ }^{19}$ w12 w21 Adding the data from the Val-HeFT subgroup not treated with an ACE inhibitor gives more support to the view that ARBs are more efficacious than placebo (table 6). However, no prospective, randomised, placebo controlled trial has, to date, tested the hypothesis that ARBs are superior to placebo in terms of morbidity/mortality or mortality end points in CHF.

One such study is currently underway. This is one of the component trials of the CHARM programme (tables 1 and 2). ${ }^{16}$

Table 7 Angiotensin receptor blocker (ARB) trials in post-myocardial infarction patients: hypotheses tested

\begin{tabular}{lllll}
\hline & Non-inferiority & & Superiority \\
\cline { 2 - 2 } & $A R B \leqslant A C E-I$ & & $A R B>A C E-I$ & $A R B+A C E-I>A C E-I$ \\
\hline OPTIMAAL & Yes $^{\star}$ & & Yes† ( 20\%, P 96\%) & No \\
VALIANT & Yes (2.5\%, P 88\%) & & Yes ( 17.5\%, P 95\%) & Yes ( 17.5\%, P 95\%) (15\%, \\
& $(0 \%, \mathrm{P} 74 \%)$ & & $(15 \%, \mathrm{P} 86 \%)$ & P 86\%) \\
\hline
\end{tabular}

$\mathrm{P}$, power - that is, power of study to detect that risk reduction

$\leqslant$, Not significantly inferior to; ${ }^{\star}$ revision of protocol as published ${ }^{\mathrm{w} 27}$ - further details not available; tassuming a captopril group annual mortality of $17 \%$.

\section{Major ARB clinical trials in CHF}

ELITE-2 compared losartan to captopril. The primary end point in this trial was all cause mortality. Mortality was not reduced by losartan compared to captopril

Val-HeFT compared valsartan to placebo, added to full conventional treatment including, in most patients, an ACE inhibitor. These were two co-primary end points - all cause mortality and morbidity/mortality. While valsartan had no effect on the former, the latter was reduced by $13 \%$ (mainly because of a $27 \%$ reduction in heart failure hospitalisation). Subgroup analysis suggested a particularly large benefit in the minority of patients not taking ACE inhibitors at baseline. More controversially, there was also the suggestion that adding valsartan to background treatment with both an ACE inhibitor and $\beta$ blocker increased risk

- The CHARM programme is still underway and comprises three component trials. One is comparing candesartan to placebo in patients intolerant of an ACE inhibitor, and the second is making the same comparison in patients taking an ACE inhibitor. The third is comparing these two treatments in patients with heart failure and preserved left ventricular systolic function. The primary end point in each individual trial is cardiovascular death or heart failure hospitalisation and all cause mortality in the overall programme

- I-PRESERVE is a trial still in the planning stage which intends to compare irbesartan to placebo in patients with heart failure, preserved left ventricular systolic function, and an increased plasma BNP concentration.

\section{A wider role for RAAS inhibition in CHF?}

The emergence of a new class of drug for RAAS inhibition also presents the opportunity to test additional questions not formally tested in previous trials with ACE inhibitors. One pressing issue in clinical cardiology is the treatment of $\mathrm{CHF}$ in patients with preserved left ventricular systolic function, who make up perhaps a third of all patients with CHF and who also have an increased morbidity and mortality. ${ }^{\text {w22 } 23}$ Though left ventricular ejection fraction (LVEF) measurements were not required for entry into either the CONSENSUS-1 or $\mathrm{V}-\mathrm{HeFT}$ studies, these trials are generally considered to have recruited patients with left ventricular systolic dysfunction. ${ }^{1 \text { w24 w25 }}$

It is possible that RAAS inhibition might also be of benefit in patients with CHF and preserved left ventricular systolic function. These patients are treated with diuretics which may be expected to cause RAAS activation. ${ }^{\mathrm{w} 26}$ 
Many are hypertensive, diabetic, and have left ventricular hypertrophy, comorbidities that might be expected to respond favourably to RAAS inhibition, especially in the light of the recently reported HOPE study. ${ }^{\mathrm{w} 27}{ }_{\text {w28 }}$ Once more, of course, this is a hypothesis that needs to be tested in an appropriately designed clinical trial. Two trials are underway. One with the ACE inhibitor perindopril (PEP-CHF) ${ }^{\mathrm{w} 29}$ and one which is a component trial of the CHARM programme (study 0007 or "preserved CHARM"). ${ }^{16}$ Another trial, with irbesartan, is at an advanced stage of planning. This trial, to be known as I-PRESERVE, will enrol patients with current signs/symptoms of heart failure (or an admission to hospital primarily because of heart failure within the last three months), an LVEF $\geqslant 0.45$, and a raised plasma brain natriuretic peptide (BNP) concentration.

\section{ARB myocardial infarction trials}

Two trials are underway in patients with acute myocardial infarction. These are OPTIMAAL and VALIANT which are outlined in table 7. OPTIMAAL is similar to the ELITE trials in comparing losartan to captopril. ${ }^{20}{ }^{21}$ The patients randomised are high risk survivors broadly similar, but not identical, to those recruited into the seminal ACE inhibitor postmyocardial infarction trials (SAVE, AIRE, TRACE). ${ }^{\text {w1-3 }}$ OPTIMAAL is sufficiently large to have a $95 \%$ power of showing a $20 \%$ relative reduction in the risk of death with losartan compared to captopril. VALIANT has a more complex design with three treatment groups (captopril, valsartan, and their combination) and is powered not just to test for superiority but also for non-inferiority (table 7 ). ${ }^{22}$

As a consequence, the patient entry criteria must exactly mirror those of the reference trials SAVE, ${ }^{\mathrm{w} 1}$ AIRE, ${ }^{\mathrm{w} 2}$ and TRACE ${ }^{\mathrm{w} 3}$. Among the questions VALIANT can address is the one of whether ARBs have similar efficacy to ACE inhibitors (non-inferiority) but are better tolerated. VALIANT will, of course, also show whether combination ACE inhibitor-ARB treatment is superior to ACE inhibitor monotherapy in the post-myocardial infarction setting.

\section{Conclusions and clinical} recommendations

It seems reasonable to recommend use of an angiotensin receptor blocker as an alternative to an ACE inhibitor in the patient truly intolerant of the inhibitor. An angiotensin receptor blocker may also be added to an ACE inhibitor to improve symptoms and reduce the risk of hospital admission with worsening heart failure. At present angiotensin receptor blockers are only indicated where there is ACE inhibitor or $\beta$ blocker intolerance.

- Angiotensin receptor blockers may be used as an alternative to an ACE inhibitor in the patient truly intolerant of an ACE inhibitor.
- Angiotensin receptor blockers may also be used in addition to an ACE inhibitor when a patient is intolerant of a $\beta$ blocker.

- "Triple neurohumoral blockade" with an ACE inhibitor, $\beta$ blocker, and angiotensin receptor blocker is not, presently, recommended.

1. The CONSENSUS Trial Study Group. Effects of enalapril on mortality in severe congestive heart failure. Results of the cooperative north Scandinavian enalapril survival study (CONSENSUS). N Engl J Med 1987;316:1429-35.

2. The SOLVD Investigators. Effect of enalapril on survival in patients with reduced left ventricular ejection fractions and congestive heart failure. N Engl J Med 1991;325:293-302

3. Garg R, Yusuf S. Overview of randomized trials of angiotensin-converting enzyme inhibitors on mortality and morbidity in patients with heart failure. Collaborative group on ACE inhibitor trials. JAMA 1995;273:1450-6.

4. Pitt B, Chang P, Timmermans PBM. Angiotensin-II receptor antagonists in heart failure-rationale and design of the evaluation of losartan in the elderly (ELITE) trial. Cardiovascular Drugs and Therapy 1995;9:693-700.

5. Granger B, Ertl G, Kuch J, et al. Randomized trial of candesartan cilexetil in the treatment of patients with congestive heart failure and a history of intolerance to angiotensin-converting enzyme inhibitors. Am Heart $J$ 2000;139:609-17.

- SPICE was a three month pilot study for CHARM study 0003 ("alternative CHARM"), comparing placebo to candesartan cilexetil in patients intolerant of an ACE inhibitor. There was no significant difference in the inhibitor. There was no significant difference in the
proportion of placebo and candesartan treated patients proportion of placebo and candesartan treat
remaining on treatment for three months.

6. Pitt B, Segal R, Martinez FA, et al. Randomised trial of losartan versus captopril in patients over 65 with heart failure (evaluation of losartan in the elderly study, ELITE). Lancet 1997;349:747-52.

- ELITE was a relatively small study set up to compare tolerability (as assessed by changes in renal function) of losartan compared to captopril. Unexpected and notably lower mortality was found in the losartan group. This study lower mortality was found in the losartan group. This study emphasises how misleading small studies and multiple analyses involving secondary and tertiary end points can
be. It actually showed no difference in the primary end point.

7. Pitt B, Poole-Wilson P, Segal R, et al. Effects of losartan versus captopril on mortality in patients with symptomatic heart failure: rationale, design and baseline characteristics of patients in the losartan heart failure survival study- Patie II Journal of Cardiac Failure 1999:5:146-54

8. Pitt B, Poole-Wilson PA, Segal R, et al. Effect of losartan compared with captopril on mortality in patients with symptomatic heart failure: randomised trial-the losartan heart failure survival study ELITE II. Lancet

2000;355:1582-7.

- One of the three "landmark" major ARB mortality or mortality/morbidity trials in heart failure either underway or completed. Essentially a repeat of ELITE, but much larger with longer term follow up and properly powered to examine mortality (the primary end point this time). The study was designed as a "superiority trial" and did not study was designed as a "superiority trial" and did not was not powered to show "non-inferiority" (losartan no worse than captopril) or equivalence (losartan as good as worse than captopril) or equiv
or equivalent to captopril).

9. Tsuyuki RT, Yusuf S, Rouleau JL, et al. Combination neurohormonal blockade with ACE inhibitors, angiotensin II antagonists and beta-blockers in patients with congestive heart failure: design of the randomized evaluation of strategies for left ventricular dysfunction (RESOLVD) pilot strategies for left ventricular dysfunction
study. Can J Cardiol 1997;13:1166-74.

10. McKelvie RS, Yusuf S, Pericak D, et al. Comparison of candesartan, enalapril and their combination in congestive heart failure: randomized evaluation of strategies for left ventricular dysfunction (RESOLVD) pilot study. The RESOLVD pilot study investigators. Circulation 1999;100:1056-64.

- RESOLVD was a relatively small and complex study designed to compare an ACE inhibitor (enalapril) with designed to compare an ACE inhibitor (enalapril) with a number of doses of an ARB (candesartan) and their combination, with subsequent randomisation to $\beta$ blocker or placebo. The primary end point was six minute wak distance (no difference between groups). Interesting observations were reported on left ventricular remodelling and neurohumoral measures.

11. Cohn JN, Tognoni G, Glazer RD, et al. Rationale and design of the valsartan heart failure trial: a large
multinational trial to assess the effects of valsartan, an multinational trial to assess the effects of valsartan, an chronic congestive heart failure. Journal of Cardiac Failure 1999;5:155-60.

- The design paper for the second of the landmark ARB

trials in heart failure. Publication of the results is awaited. 
website

extra

Additional references

appear on the

Heart website

www.heartjnl.com
12. Dunselman PHJM. Effects of the replacement of the angiotensin converting enzyme inhibitor enalapril by the angiotensin II receptor blocker telmisartan in patients with congestive heart failure. The replacement of angiotensin converting enzyme inhibition (REPLACE) investigators. Int Cardiol 2001;77:131-8.

13. Baruch L, Anand I, Cohen IS, et al. Augmented short and long term hemodynamic and hormonal effects of an angiotensin receptor blocker added to angiotensin converting angiotensin receptor blocker added to angiotensin conve enzyme inhibitor therapy in patie
Circulation 1999;99:2658-64

14. Hamroff G, Katz SD, Mancini D, et al. Addition of angiotensin II receptor blockade to maximal capacity in patients with severe congestive heart failure. Circulation 1999:99:990-2.

- A small but intriguing study. Very well designed

- A small but intriguing study. Very well designed comparison of placebo or ARB (losartan) added to full advanced heart failure. Impressive improvements were advanced heart failure. Impressive improvements were found in clinical status and exe

15. Cohn JN, Tognoni G, Glazer R, et al. Baseline demographics of the valsartan heart failure trial. Eur J Heart demographics of the valse
Failure 2000;2:439-46.

16. Swedberg K, Pfeffer M, Granger C, et al. Candesartan in heart failure-assessment of reduction in mortality and morbidity (CHARM): rationale and design. Journal of Cardiac Failure 1999;3:276-82.

- The design paper for the third of the landmark ARB trials in heart failure. The CHARM programme consists of three component trials that are currently in their follow up phase: "alternative CHARM" (in ACE inhibitor intolerant patients), "added CHARM" (in ACE inhibitor treated patients), and "preserved CHARM" (in patients with preserved left ventricular systolic dysfunction).

17. Havranek EP, Thomas I, Smith WB, et al. Dose-related beneficial long-term hemodynamic and clinical efficacy of irbesartan in heart failure. J Am Coll Cardiol

1999;33:117-81.

18. Riegger GAJ, Bouzo $\mathbf{H}$, Petr $\mathbf{P}$, et al. Improvement in exercise tolerance and symptoms of congestive heart failure during treatment with candesartan cilexetil. Circulation 1999;100:2224-30.

19. Erdmann E, George M, Voet B, et al. The safety and tolerability of candesartan cilexetil in CHF. Journal of the Renin Angiotensin Aldosterone System 2000;1:31-6.

20. Dickstein K, Kjekshus J. Comparison of the effects of losartan and captopril on mortality in patients after acute myocardial infarction: the OPTIMAAL trial design. Am $J$ Cardiol 1999;83:477-81.

21. Dickstein K, Kjekshus J, for the OPTIMAAL Trial Steering Committee and Investigators. Comparison of baseline data, initial course, and management: losartan versus captopril following acute myocardial infarction (the OPTIMAAL trial). Am J Cardiol 2001:87:766-71.

22. Pfeffer MA, McMurray J, Leizorovicz A, et al. Valsartan in acute myocardial infarction trial-VALIANT: rationale and design. Am Heart J 2000;140:727-50. 